\title{
The Relationship of Self-Presentation, Stress Coping, and Competitive State Anxiety in Elite Athletes
}

\author{
Seo-Jin Youn ${ }^{1}$ and Tai-Seok Chang ${ }^{2 *}$ \\ ${ }^{1}$ Global Research Institute for Arts \& Culture Education, Sangmyung University, Seoul, Korea \\ ${ }^{2}$ Korea Institute of Sports Science, Seoul, Korea
}

\author{
Article Info \\ Received 2021.07.24. \\ Revised 2021.09.09. \\ Accepted 2021.09.16. \\ Correspondence* \\ Tai-Seok Chang \\ jaygoon@skku.edu

\section{Key Words} \\ Elite athletes, \\ Self-presentation, \\ Stress Coping, \\ Competitive state anxiety
}

PURPOSE The purpose of this study was to verify the mediated effect between selfpresentation, stress coping, and competitive state anxiety among domestic elite athletes and to identify the intermediate effects of stress coping in the relationship between self-presentation and competitive state anxiety. METHODS The study was conducted with 259 elite athletes. The relationship between self-presentation, stress coping and competitive state anxiety was verified using the SPSS and AMOS. RESULTS The results of this study were as follows. First, Self-presentation affected positively on stress coping. Second, Stress coping affected positively on competitive state anxiety. Third, Self-presentation affected positively on competitive state. Lastly, stress coping mediated significantly the relationship between self-presentation and competitive state anxiety. CONCLUSIONS The result of this study shows that the competitive anxiety of elite athletes depends on the meaning of self-presentation, and the stress coping is deeply related to competitive state anxiety. In conclusion, it was determined that it provided basic data to understand the competitive state anxiety of players in various ways.

\section{서론}

프로 스포츠에서 우수성을 인정받은 엘리트 운동선수들은 치열한 경쟁 속에서 운동 성과라는 목표를 달성하기 위하여 운동을 수행한다. 경쟁 스포츠의 내재적 측면은 압박을 받는 상황에서도 선수들은 경쟁의 요구 를 충족하고 운동 수행을 해야 한다는 것이다. 이러한 압박 상황에서 선 수 개인이 경쟁의 요구를 어떻게 인식하는지에 따라 경기의 자연스러운 부분으로 인식할 수도 있고 스트레스를 받는 상황으로 해석할 수 있다. 여기서 스트레스는 경쟁 요구를 충족하지 못하는 것이 곧 중요한 결과를 초래하는 것으로 인식되며, 인지 및 신체 상태 불안이 증가 된 수준으로 대응되는 조건에서 환경적 요구와 대응 능력 사이의 실질적인 불균형에 대한 인식을 포함하는 과정을 말한다(Martens et al., 1990). 이처럼 스 트레스가 많고 불안을 유발하는 상황에서 일부 운동선수는 신체 및 정신 적인 기능이 저하되는 것을 경험하는 것으로 관찰되었다. 따라서 스포츠 심리학자들은 불안과 운동 성과의 관계에 대해 상당한 관심을 가졌으며 (Craft et al., 2003), 선수들의 경쟁불안에 관한 주제가 가장 널리 연구 되고 있다(Woodman \& Hardy, 2001). 경쟁불안에 관한 연구를 살펴 보면 경쟁불안의 증상과 성과 결과에 중점을 둔 연구방향에서 경쟁불안 의 원인에 대한 이해를 높여주며, 이론적 관점을 정립하고자 자기-제시 걱정(self-presentational concerns)에 초점을 맞춘 Leary(1992)의 경
쟁불안 개념화를 확장하기 시작했다(McGowan et al., 2008).

Leary(1992)는 스포츠 상황에서 일어나는 경쟁불안의 본질을 자기제시 과정으로 파악할 수 있다고 주장하였다. 즉, 경쟁불안은 경쟁 상황 에서 자기-제시의 영향으로 나타나며, 타인에게 인식되는 자신의 능력 에 대한 의심에서 비롯된 사회적 평가 과정의 특성과 전적으로 부합한다 고 하였다.

자기-제시 이론은 개인이 자신의 특정 이미지를 다른 사람에게 제시 하려는 동기이며, 개인이 나타내고자 하는 자기 이미지의 유형은 개인의 성향과 상황적 요소에 따라 달라진다(Tseelon, 1992). 이러한 자기-제 시의 목표는 개인이 다른 사람에게 좋은 인상을 주는 것을 중요하게 여 기는 것이지만 자기 효능감이 낮은 개인은 평가에 대한 두려움으로 이어 질 수 있다(Leary \& Jongman-Sereno, 2014). 운동선수는 경쟁 상황에 서 보여지는 자신의 무능력함, 비숙련, 경쟁 요구를 처리할 수 없는 이미 지가 팀 선택 및 연봉 등 자신의 가치에 부정적 영향을 미칠 수도 있으므 로 다른 사람에게 주는 자신의 인상에 관심을 가진다(Lorimer, 2006). 이러한 이유로 선수들은 자신의 인상을 능숙하게 관리할 필요가 있다.

운동선수가 자기-제시를 통해 목표를 달성하려는 욕구는 선수의 인 지, 감정 및 행동에 상당한 영향을 미칠 수 있으며, 특히 경기 전의 감정 이 실제 경기성과에 영향을 줄 수 있기 때문에 경쟁 상황을 시작하기 전 운동선수의 감정에 대한 자기-제시 표현 방식을 조사하는 것이 중요하다 
(Podlog et al., 2013). 이렇듯 운동 수행에 대한 감정의 영향을 강조하는 다양한 연구를 고려할 때, 자기-제시 이론은 실용적으로 가치 있는 연구 라고 할 수 있다.

국외 선행연구에서 자기-제시는 인지 및 신체적 불안과 관련이 있다 고 하였으며, 부정적인 평가에 대한 두려움이 높은 농구 선수들은 불안 감이 크게 증가하고 성과가 현저히 감소하는 것으로 나타났다(Mesagno et al., 2011). 그러므로 운동 수행에서 나타나는 스트레스와 불안의 역 할과 원인을 이해해야하며, 자기-제시와의 관계는 반드시 검증되어야 한다고 하였다(Williams et al., 1999). 선수들은 스트레스가 있는 상태 에서 운동수행을 하게 되면 불안을 경험할 가능성이 높으며, 작업기억을 통해 처리되는 정보의 처리 능력이 감소하기 때문에 운동수행에 부정적 인 영향을 미치게 된다(Eysenck \& Calvo, 1992).

또 다른 연구에서는 스트레스 상황에서 자기-제시와 대처는 함께 고 려해야 한다고 주장되었다. 운동선수들의 성공적인 대처능력은 경쟁 불 안을 완화 시킬 수 있다고 하였으며, 대처와 스포츠 관련 연구에 따르 면 개인은 다양한 문제 중심, 감정 중심 및 회피 대처 전략을 사용하여 다양한 상황에서 다르게 사용한다는 것을 보고하였다(Ntoumanis, \& Biddle, 2000).

대처는 자신의 능력에 부담을 주거나 초과하는 것으로 평가되는 특정 한 상황에서 개인이 겪는 스트레스를 최소화하기 위해 지속적으로 변화 하는 인지 및 행동적 노력을 의미한다(Lazarus \& Folkman, 1984). 여 기서 정의된 '인지 및 행동 노력'에 기반하여 문제 중심과 감정 중심으 로 크게 분류된다. 문제 중심 대처는 개인과 환경 사이의 스트레스 관계 (즉, 도전적이거나 위협적이거나 유해한 상황)의 영향을 확인, 해결 또는 최소화하기 위한 노력을 의미하며, 감정 중심의 대처는 현재 상황을 직 접적으로 바꾸는 것이 아니라 문제에 대한 감정적 반응을 조절하거나 감 정적 고통을 줄이기 위한 것이다.

운동선수들이 스트레스가 많은 상황을 관리하기 위해 사용하는 대처 전략은 불안감에 영향을 미치며 이는 곧 경기성과에 영향을 준다고 하였 다(Dias et al., 2010).

따라서 대처는 선수의 자기 규제(self-regulation)를 촉진할 수 있 는 과정 중 하나이며 선수가 어려운 운동 경기의 요구를 성공적으로 충 족시킬 수 있는지 결정하는 중요한 요소이다(Hanin, 2000; Lazarus, 2000; Nicholls \& Thelwell, 2010). 또한 대처는 문제와 부정적인 감정 에 대한 반응일뿐만 아니라 긍정적인 심리적, 정서적 성장을 촉진하기 위해 계획적이고 능동적인 인지 및 행동을 포함한다고 판단할 수 있다 (Tamminen et al., 2014).

앞서 언급한 바와 같이 자기-제시는 경쟁불안의 원인을 이해하는 데 도움을 주며, 스트레스 대처는 경쟁불안을 완화 시켜 주는 심리적 요인 임이 분명하나 국내외 연구에서는 이와 관련된 연구가 미비하다. 이에 본 연구에서는 자기-제시는 친밀하고 장기적인 관계보다는 지도자나 동 료와 같은 사회 집단에서 나타난다는 근거(Leary \& Jongman-Sereno, 2014)를 토대로 국내 엘리트 팀 종목 운동선수들을 대상으로 스포츠 상 황에서 나타나는 자기-제시와 경쟁불안의 관계를 규명하고 더 나아가 스트레스 대처의 매개 효과를 검증하고자 한다. 이는 운동선수들이 느끼 는 경쟁불안의 이론적 확장에 기여하며, 스포츠 상황에서 나타나는 선수 들의 심리 상태를 이해하는 데 도움이 될 것이다. 구체적인 가설은 다음 과 같다. 첫째, 엘리트 운동선수의 자기-제시는 스트레스 대처에 유의한 영향을 미칠 것이다. 둘째, 스트레스 대처는 경쟁상태불안에 유의한 영 향을 미칠 것이다. 셋째, 자기-제시는 경쟁상태불안에 유의한 영향을 미 칠 것이다. 넷째, 자기-제시와 경쟁상태불안의 관계에서 스트레스 대처 는 매개역할을 할 것이다.

\section{연구방법}

\section{연구대상}

본 연구는 2020년 국내 실업팀에 소속된 팀 종목 선수들을 대상으로 설 문조사를 진행하였다. 자료 수집은 코로나-19로 인하여 먼저 종목 지도 자에게 연구 취지를 설명하고 동의를 구한 후 비대면 설문조사를 진행 하였다. 선수들에게 온라인을 통해 설문에 응답하게 하였으며, 무응답, 편향적 기입 등 불성실한 설문지를 제외하고 총 259부를 최종 분석하였 다. 구체적인 일반적 특성은 〈Table 1〉과 같다.

\section{측정도구}

\section{1. 자기-제시}

국내 엘리트 운동선수의 스포츠 자기-제시 질문지를 측정하기 위하 여 Wilson \& Eklund(1998)가 개발하고 김영숙, 윤서진, 박인천, 송용관 (Kim et al., 2020)이 번안한 설문지를 사용하였다. 설문 문항은 '다른 사 람들의 기대에 부응하지 못하게 보일까봐 걱정된다.' 등의 내용으로 피 곤 ·에너지 부족 걱정 12 문항, 경기력 부족 걱정 10 문항, 운동선수로서 의 재능 부족 걱정 7 문항, 신체·외모 걱정 3문항으로 4점 척도로 구성하 였다. 확인적 요인 분석을 실시한 결과를 살펴보면, 적합도 지수는 $\mathrm{x}^{2}(\mathrm{df})$ $=585.923(227), \mathrm{CFI}=.912$, TLI $=.893, \mathrm{IFI}=.913, \mathrm{GFI}=.844, \mathrm{RMR}=$ $.044, \mathrm{RMSEA}=.078$ 로 구성모형의 타당성이 비교적 적합한 수준으로 검 증되었다. 또한 표준화 요인적재치 .5이상의 기준치를 벗어난 1 번, 4 번, 11 번, 17 번, 21 번, 22번, 26번, 30번 문항을 제외하고 경기력 부족 걱정 8 문항, 피곤·에너지 부족 걱정 8 문항, 운동선수로서의 재능 부족 걱정 5 문항, 신체·외모 걱정 3 문항으로 총 24 문항을 재구성하여 분석하였다. 그 결과 〈Table 2〉에 제시한 바와 같이 적합한 수준으로 나타났다.

\section{2. 스트레스 대처}

국내 엘리트 운동선수의 스트레스 대처를 측정하기 위하여 유진, 박성 준(1998)이 개발한 KASCS(Korean Athlete Sport Coping Scale)를 사 용하였다. 설문 문항은 '나 자신을 시험할 수 있는 좋은 계기로 생각한 다.' 등의 내용으로 문제 중심 대처 8 문항, 정서 중심 대처 8 문항, 초연 8

Table 1. Research subject characteristics

\begin{tabular}{cc|ccc}
\hline & & $\mathrm{n}$ & Ratio(\%) & Total(\%) \\
\hline \multirow{2}{*}{ Sex } & Male & 161 & 62.1 & 259 \\
\cline { 2 - 4 } & Female & 98 & 37.9 & $(100)$ \\
\hline \multirow{3}{*}{ Career } & $5 \mathrm{y} \sim 10 \mathrm{y}$ & 70 & 27 & \\
\cline { 2 - 4 } & $10 \mathrm{y} \sim 15 \mathrm{y}$ & 152 & 58.6 & 259 \\
\cline { 2 - 4 } & $15 \mathrm{y} \sim 20 \mathrm{y}$ & 37 & 14.2 & \\
\hline \multirow{2}{*}{ Age } & 20 's & 208 & 80.3 & 259 \\
\cline { 2 - 4 } & 30 's & 51 & 19.6 & $(100)$ \\
\hline \multirow{3}{*}{ Sports } & Basketball & 52 & 20.1 & \\
\cline { 2 - 4 } & Handball & 69 & 26.6 & \\
\cline { 2 - 4 } & Soccer & 60 & 23.1 & $(100)$ \\
\cline { 2 - 4 } & Field hockey & 78 & 30.1 & \\
\hline
\end{tabular}


Table 2. Latent factor reliability and mean variance extraction index for the construct

\begin{tabular}{|c|c|c|c|c|c|}
\hline & Variable & Factor loading & C.R & AVE & $\alpha$ \\
\hline \multirow{4}{*}{ Self-Presentation } & Performance / Composure inadequacy & $.694 \sim .798$ & .916 & .576 & .904 \\
\hline & Fatigued / Lacking energy & $.712 \sim .839$ & .926 & .612 & .922 \\
\hline & Physical appearance & $.778 \sim .824$ & .849 & .652 & .829 \\
\hline & Athletically untalented & $.608 \sim .813$ & .873 & .580 & .862 \\
\hline \multirow{4}{*}{ Stress coping } & Problem focused & $.708 \sim .857$ & .935 & .673 & .925 \\
\hline & Emotion focused & $.716 \sim .791$ & .912 & .633 & .879 \\
\hline & Detached & $.708 \sim .883$ & .897 & .637 & .853 \\
\hline & Avoidance & $.570 \sim .823$ & .870 & .532 & .841 \\
\hline \multirow{3}{*}{$\begin{array}{l}\text { Competitive } \\
\text { state anxiety }\end{array}$} & Cognitive anxiety & $.65 \sim .757$ & .883 & .486 & .864 \\
\hline & Physical anxiety & $.656 \sim .742$ & .898 & .523 & .885 \\
\hline & Confidence & $.44 \sim .771$ & .781 & .427 & .768 \\
\hline
\end{tabular}

문항, 회피 8문항으로 '전혀 그렇지 않다' 1점에서 '매우 그렇다' 5점 척 도로 구성하였다. 확인적 요인 분석을 실시한 결과를 살펴보면, 적합도 지수는 $\mathrm{x}^{2}(\mathrm{df})=542.573(214), \mathrm{CFI}=.925, \mathrm{TLI}=.903, \mathrm{IFI}=.926, \mathrm{GFI}=$ $.848, \mathrm{RMR}=.046, \mathrm{RMSEA}=.077$ 로 구성모형의 타당성이 비교적 적합 한 수준으로 검증되었다. 표준화 요인적재치 .5이상의 기준치를 벗어난 7번, 13번, 16번, 17번, 23번, 24번, 31번, 32번 문항을 제외하고 문제 중심 대처 7 문항, 정서 중심 대처 6 문항, 초연 5 문항, 회피 6 문항으로 총 24 문항을 재구성하여 분석하였다. 그 결과 〈Table 2〉에 제시한 바와 같 이 적합한 수준으로 나타났다.

\section{3. 경쟁상태불안}

국내 엘리트 운동선수의 경쟁 상태 불안을 측정하기 위하여 Martens et al.(1990)의 시합 상태불안 검사지(CSAI-2)를 사용하였다. CSAI-2는 '경기를 못 할까봐 걱정이 된다.' 등의 내용으로 인지적 상태불안 9문항, 신체적 상태불안 9문항, 상태 자신감 9문항으로 '전혀 그렇지 않다' 1점 에서 '매우 그렇다' 5점 척도로 구성되었다. 확인적 요인 분석을 실시한 결과를 살펴보면, 적합도 지수는 $\mathrm{x}^{2}(\mathrm{df})=368.777(161), \mathrm{CFI}=.917$, TLI $=.892, \mathrm{IFI}=.918, \mathrm{GFI}=.884, \mathrm{RMR}=.054, \mathrm{RMSEA}=.071$ 로 구성모형 의 타당성이 비교적 적합한 수준으로 검증되었다. 표준화 요인적재치 .5 이상의 기준치를 벗어난 1 번, 9번, 14 번, 15 번, 18 번, 24 번 문항을 제외 하고 인지적 상태불안 8문항, 신체적 상태불안 8 문항, 상태 자신감 5 문 항으로 총 21 문항을 재구성하여 분석하였다. 그 결과 〈Table 2〉에 제시 한 바와 같이 적합한 수준으로 나타났다.

\section{자료처리}

자료처리는 SPSS 25.0과 AMOS 25.0 프로그램을 활용하였으며, 모든 통계적 유의 수준은 .05로 설정하였다. 분석은 엘리트 운동선수의 일반 적 특성을 파악하기 위하여 빈도분석을 시작으로 측정도구의 신뢰도 분 석과 확인적 요인분석을 실시하였다. 또한 기술통계 분석과 상관관계분 석을 실시하였으며, 모형의 적합도 및 자기-제시와 경쟁 상태 불안 관계 에서 스트레스 대처의 매개효과를 확인하기 위해 구조방정식 모형을 실 시하였다.

\section{연구결과}

\section{기술통계 및 상관관계 분석}

국내 엘리트 운동선수의 자기-제시와 스트레스 대처, 경쟁 상태 불안의 수준을 파악하기 위해 기술통계 분석을 실시하였다. 그 결과 〈Table 3〉 에 제시한 바와 같이 모든 변수들이 정규성 가정을 만족하는 것으로 나 타났다. 또한 주요변인간의 관계를 검증하기 위해 상관관계분석을 실시 한 결과 문제 중심 대처와 상태 자신감은 부(-)적 상관관계를 보였으며 $(\mathrm{r}=-.030)$, 나머지 모든 하위요인은 정적 상관관계를 보였다 $(\mathrm{r}=.157$ .854).

\section{연구모형의 적합성 검증}

연구모형의 적합도를 검증하기 위해 Steiger(1990)가 제시한 $x^{2}$, RMSEA, CFI, TLI 지수의 값을 활용하였다. 검증 결과 $\mathrm{x}^{2}(\mathrm{df})=195.801$ (41), CFI $=.906$, TLI $=.874, \mathrm{IFI}=.907, \mathrm{RMSEA}=.121, \mathrm{RMR}=.056$ 로 나타나 구조모형은 비교적 수용할 수준으로 나타났다(〈Table 4〉).

\section{연구가설 검증}

구조 방정식 모형을 검증한 결과 자기-제시가 스트레스 대처에 유의한 정 $(+)$ 의 영향을 미치는 것으로 나타났고( $\beta=.805, \mathrm{p}$ <.001), 스트레스 대 처는 경쟁 상태 불안에 유의한 정(+)의 영향을 미치는 것으로 나타났다 $(\beta=.364, \mathrm{p}<.01)$. 또한 자기-제시는 경쟁 상태 불안에 의한 정(+)의 영 향을 미치는 것으로 나타났다( $\beta=.396, \mathrm{p}\langle .001)\langle T a b l e ~ 5\rangle$.

자기-제시와 경쟁 상태 불안 간의 관계에서 스트레스 대처의 매개효 과를 검증하기 위해 bootstrapping 검증을 실시하였다. 신뢰수준 95\% 를 기준으로 부트스트랩 표본수는 2,000으로 설정하여 통계적 유의성 여부를 판단하였다. 그 결과는 〈Table 6)과 같으며, 자기-제시가 스트 레스 대처를 매개하여 경쟁 상태 불안에 미치는 간접효과는 정(+)적으로 유의하게 나타났다( $\beta=.293, \mathrm{p}$ <.001). 이는 자기-제시와 경쟁 상태 불안 사이에서 스트레스 대처는 부분매개역할을 하는 것을 의미한다. 
Table 3. Descriptive Statistical Analysis and Correlation

\begin{tabular}{|c|c|c|c|c|c|c|c|c|c|c|c|}
\hline & 1 & 2 & 3 & 4 & 5 & 6 & 7 & 8 & 9 & 10 & 11 \\
\hline Performance / Composure inadequacy & 1 & & & & & & & & & & \\
\hline Fatigued / Lacking energy & $.713 * *$ & 1 & & & & & & & & & \\
\hline Physical appearance & $.607 * *$ & $.678 * *$ & 1 & & & & & & & & \\
\hline Athletically untalented & $.635^{* *}$ & $.746^{* *}$ & $.612 * *$ & 1 & & & & & & & \\
\hline Problem focused & $.376^{* *}$ & $.284 * *$ & $.234 * *$ & $.380 * *$ & 1 & & & & & & \\
\hline Emotion focused & $.545^{* *}$ & $.422 * *$ & $.425^{* *}$ & $.446 * *$ & $.683 * *$ & 1 & & & & & \\
\hline Detached & $.480 * *$ & $.417 * *$ & $.382 * *$ & $.409 * *$ & $.282 * *$ & $.433 * *$ & 1 & & & & \\
\hline Avoidance & $.595^{* *}$ & $.548^{* *}$ & $.544 * *$ & $.528 * *$ & $.307 * *$ & $.482 * *$ & $.510 * *$ & 1 & & & \\
\hline Cognitive anxiety & $.594 * *$ & $.533^{* *}$ & $.521^{* *}$ & $.530 * *$ & $.329 * *$ & $.475^{* *}$ & $.455^{* *}$ & $.500 * *$ & 1 & & \\
\hline Physical anxiety & $.561 * *$ & $.461^{* *}$ & $.516^{* *}$ & $.485^{* *}$ & $.212 * *$ & $.424 * *$ & $.407 * *$ & $.489 * *$ & $.854 * *$ & 1 & \\
\hline Confidence & $.302 * *$ & $.204 * *$ & $.297 * *$ & $.135^{*}$ & $-.030 *$ & $.157 *$ & $.296 * *$ & $.266 * *$ & $.319^{* *}$ & $.362 * *$ & 1 \\
\hline $\mathrm{M}$ & 2.2162 & 2.0893 & 1.8919 & 2.0085 & 2.3658 & 2.2111 & 3.5877 & 3.3104 & 2.3316 & 2.2326 & 2.5174 \\
\hline SD & .73323 & .78561 & .84520 & .74548 & .90466 & .91467 & 1.19513 & 1.49002 & .69574 & .71320 & .65115 \\
\hline Skew & .013 & .112 & .523 & .215 & .027 & .167 & -.128 & .445 & -.116 & .167 & .147 \\
\hline Kurtosis & -.860 & -1.109 & -.870 & -.755 & 2.748 & 2.830 & -.193 & -.038 & -.567 & -.679 & -.502 \\
\hline
\end{tabular}

${ }^{*} \mathrm{p}<.05$

Table 4. Relevance of the research model

\begin{tabular}{c|ccccccc}
\hline & $\mathrm{x}^{2} /(\mathrm{df})$ & $\mathrm{p}$ & TLI & IFI & CFI & RMSEA & RMR \\
\hline Value & $195.801(41)$ & .000 & .874 & .907 & .906 & .121 & .056 \\
\hline
\end{tabular}

Table 5. Path analysis

\begin{tabular}{clc|cccc}
\hline & Path & & B & S.E. & $\beta$ & Z \\
\hline Self-Presentation & $\rightarrow$ & Stress coping & .685 & .084 & .805 & $8.144^{* * *}$ \\
\hline Stress coping & $\rightarrow$ & Competitive state anxiety & .449 & .152 & .364 & $2.957^{* *}$ \\
Self-Presentation & $\rightarrow$ & Competitive state anxiety & .416 & .120 & .396 & $3.459^{* * *}$ \\
\hline
\end{tabular}

$* * * \mathrm{p}<.001, * * \mathrm{p}<.01$

Table 6. Direct and indirect effects through bootstrap

\begin{tabular}{clc|ccc}
\hline & Path & & Direct Effects & Indirect Effects & Total Effects \\
\hline Self-Presentation & $\rightarrow$ & Stress coping & $.805^{* * *}$ & $.805^{* * *}$ \\
\hline Stress coping & $\rightarrow$ & Competitive state anxiety & $.364^{* *}$ & $.364^{* *}$ \\
Self-Presentation & $\rightarrow$ & Competitive state anxiety & $.396^{* * *}$ & $.293^{* * *}$ & $.689^{* * *}$ \\
\hline
\end{tabular}

$* * * \mathrm{p}<.001, * * \mathrm{p}<.01$

Table 7. Mediating Effect Verification

\begin{tabular}{|c|c|c|c|c|c|}
\hline \multirow{2}{*}{ Path } & \multirow{2}{*}{ Indirect effects } & \multirow{2}{*}{ S.E. } & \multirow{2}{*}{ Sig } & \multicolumn{2}{|c|}{ Bootstrapping BC 95\% CI } \\
\hline & & & & Lower & Upper \\
\hline $\begin{array}{c}\text { Self-Presentation } \rightarrow \text { Stress coping } \rightarrow \\
\text { Competitive state anxiety }\end{array}$ & .293 & .193 & .026 & .027 & .772 \\
\hline
\end{tabular}




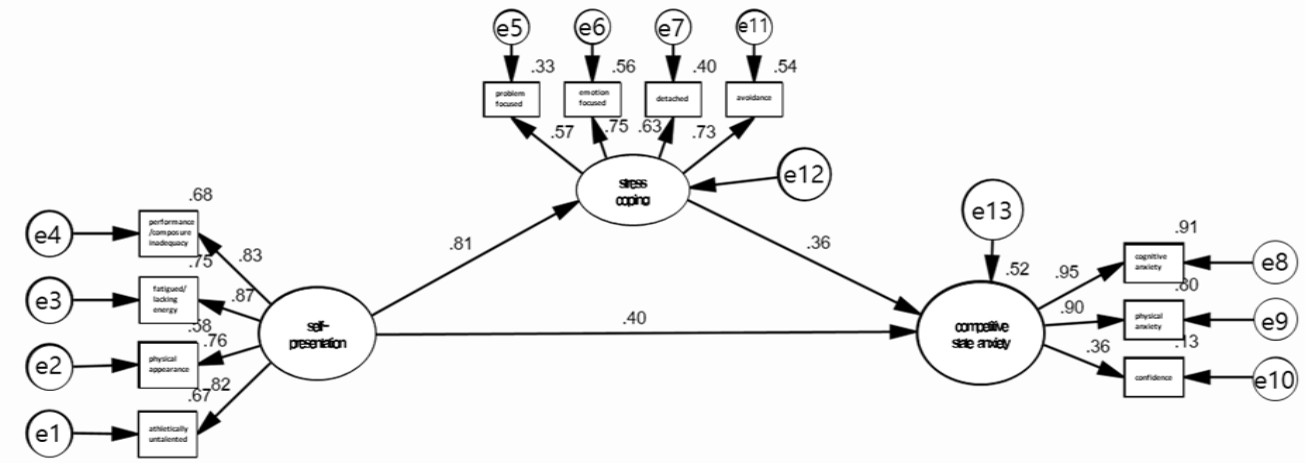

Fig. 1. Structural model verification result

\section{논의}

본 연구는 국내 엘리트 운동선수들에게 나타나는 경쟁불안의 원인을 이 해하고자 자기-제시와 스트레스 대처, 경쟁 상태불안의 관계를 검증하 였다. 국외 선행 연구를 살펴보면 경쟁불안을 자기-제시 이론과 함께 개 념화하는 연구가 진행되고 있지만, 반면 국내에서는 자기-제시에 관한 측정도구의 타당성만 검증되었을 뿐 경쟁불안과의 관계를 검증한 연구 는 미비한 상황이다. 따라서 본 연구를 통해 자기-제시 이론에 초점을 맞춰 경쟁불안을 이해하는 데 도움이 될 것이라 판단된다. 구체적인 논 의는 다음과 같다.

연구결과 자기-제시, 스트레스대처, 경쟁 상태불안 간 유의한 영향을 미치는 것으로 나타났으며, 스트레스 대처는 자기-제시와 경쟁 상태불 안의 관계에서 매개역할을 하는 것을 확인할 수 있었다.

시합상황에서 선수들의 경쟁불안은 다양한 원인으로 나타나지만, 이 러한 경쟁불안의 본질은 자기-제시 과정으로 규명할 수 있다고 하였다 (Leary \& Kowalski, 1990).

인지 불안은 운동선수의 기대와 관련한 인식에서 비롯되며, 신체불안 은 환경적 자극에 대한 조건화된 반응에서 나타낼 수 있다(Parfitt et al., 1990). 선수들은 경기 중에 선수로서 경쟁 요구에 준비되어 있지 않아 미숙하고, 무능력한 이미지를 투사할 수 있으며, 더불어 경쟁 압박을 감 당할 수 없는 이미지를 지도자 및 팀원, 관중에게 비춰질 수 있는 위험 이 있다(Leary, 1992). Martin과 Mack(1996)는 사회적 체격 불안 및 신 체 표현 자신감은 경쟁적 특성 불안의 중요한 예측 인자라고 하였다. 또 한 스트레스가 많은 목표 관련 상황에서 자기-제시 걱정은 사회적 불안 과 과제 수행에 영향을 줄 수 있으며, 스포츠 상황에서 중요한 역할을 한 다고 하였다(Kim et al., 2020). 연습이나 시합을 수행하는데 있어서 선 수들에게 좋은 인상을 가져야 한다는 걱정을 만들기 때문에 개인의 정 체성을 위해서는 자기제시의 문제점을 알고 대처하는 것이 중요하다 (Mesagno et al., 2011). 또한 개인의 신념을 뒷받침하는 개인 이미지를 만들려고 시도하기 때문에 자기제시는 스트레스에 중요한 역할을 할 수 있다고 하였다(Leary, 2001).

이러한 선행연구들은 선수들의 자기-제시의 사용은 운동상황에서 발 생할 수 있는 스트레스 상황에 대한 대처가 중요하게 작용한다는 본 연 구의 결과를 지지해주며, 불안을 낮추는데 효과적인 방법으로 사용될 수 있다는 것을 의미한다.

다음은 자기-제시가 스트레스 대처에 정적 영향을 미친 결과에 대해 논의하고자 한다. 자기-제시는 다른 사람들이 자신을 형성하는 인식을 통제하려고 시도하는 과정이며(Leary \& Kowalski, 1990), 대처는 특정 상황에서 외적, 내적 요구를 관리하기 위해 지속적으로 변화하는 인지
및 행동적 노력이라고 할 수 있다(Lazarus \& Folkman, 1984).

자기-제시 모델에서는 선수들의 특정 성격 요인이 스트레스와 인지상 태 불안 증가에 더 큰 영향을 주며, 압박 상황에서 불안이 심화된다고 하 였다(Mesagno et al., 2015).

즉, 자기-제시와 스트레스 대처는 자신의 능력을 의심받거나 초과되 는 상황에서 자신을 관리하기 위해 인지와 행동을 변화시키는 과정이라 고 볼 수 있다. 부정적인 평가에 대한 걱정은 다른 사람들에 의해 부정적 인 평가를 받을 가능성에 대해 나타나는 현상이라고 설명할 수 있다. 이 러한 현상이 발생되면 문제나 정서에 초점을 맞춰 대처하는 것은 당연한 일이라고 생각된다. 더 나아가 불안의 원인을 파악하고 대처한다면 선수 들은 경쟁 상황에서 경쟁의 요구를 능동적으로 해결할 수 있으며 이는 경기 성과에도 긍정적 영향을 미칠 것이라 판단된다.

스트레스 대처와 경쟁 불안의 관계를 검증한 연구에서는 선수들이 가 지는 문제점에 대한 적극적 대처는 문제 중심적 대처와 관련이 있고 수 동적 대처는 회피 대처 전략과 관련이 있다고 하였다. 또한 적극적 대처 는 불안을 감소시키는 데 있어 수동적 대처보다 더 효과적이라고 하였 다(Shin \& Kim, 2005). 이렇듯 스트레스 대처는 경쟁 상태불안과 깊은 관련이 있음을 확인할 수 있었으며 본 연구 결과도 선행연구를 지지해 주고 있다.

마지막으로 국내 엘리트 운동선수들의 스트레스 대처는 자기-제시와 경쟁상태 불안 간에 매개 역할을 한 결과를 논의하고자 한다.

운동선수들의 자기-제시 방법 활용에 있어서 낮은 효율성이 발생되는 경우나 압박 상황에서 좋은 인상을 유지할 수 있는 능력이 의심되면 선 수들은 높은 수준의 불안을 경험하게 되고 이는 주의 산만, 자기 집중 저 하, 불안 등과 같은 스트레스 상황에 놓이게 된다(Hill et al., 2017).

이러한 불안을 완화시키기 위해서는 선수들은 신체적 기술뿐만 아 니라 정신적, 심리적 요인들도 지속적으로 변화하여야 하며, 대처 전 략을 통해 선수들의 의지와 행동을 변화시켜야 한다고 제시하고 있다 (Lazarus, 1999; Skinner \& Zimmer-Gembeck, 2007). 이는 선수들 이 경쟁 상황에서 불안을 조절하기 위해서 스트레스 요인, 감정, 인지, 행동, 생리적 반응에 대한 평가와 합리적이고 계획된 행동 및 대처 반응 을 지속적으로 관리해야함을 의미한다.

이러한 선행연구와 본 연구 결과를 토대로 선수들은 경쟁상황에서 나 타나는 불안에 대한 이해와 함께 자기-제시 전략과 스트레스 대처 전략 을 고려하여 사용해야 한다고 판단할 수 있다.

종합적으로 자기-제시는 인간의 대인 관계에서 나타나는 자연스러운 행동이며, 자신의 행동에 대한 자기 표현적 의미를 무시할 수 없는 사회 적 상황에서 나타난다고 판단된다(Goffman, 1959). 따라서 운동선수 들은 다른 사람들이 원하는 방식으로 자신의 행동을 변화시키며, 스포츠 
상황에서 경험하는 경쟁 스트레스가 경험 자체보다는 자기 표현적 의미 에 크게 기인한다고 볼 수 있다(Leary, 1992). 본 연구를 통해 선수들이 느끼는 경쟁 불안은 자기-제시의 의미에 의존한다고 볼 수 있으며, 더 나아가 스트레스 대처는 경쟁 불안과 깊은 관련이 있음을 알 수 있었다. 선수들의 경쟁불안을 이해하고, 완화시킨다면 선수들의 성공적 성과를 이루는 발판이 될 것이다.

\section{결론 및 제언}

본 연구는 국내 엘리트 운동선수를 대상으로 자기-제시, 스트레스 대처, 경쟁 상태불안의 관계를 검증하고 자기-제시와 경쟁 상태불안의 관계에 서 스트레스 대처의 매개효과를 확인하는 데 목적이 있었다.

그 결과 첫째, 엘리트 운동선수의 자기-제시와 스트레스 대처는 정적 인 영향이 있었다. 둘째, 스트레스 대처와 경쟁상태불안은 정적인 영향 이 있었다. 셋째, 자기-제시와 경쟁상태불안은 정적인 영향이 있었다. 넷째, 자기-제시와 경쟁상태불안 관계에서 스트레스 대처는 부분매개 역할을 하였다. 결론적으로 자기-제시와 스트레스 대처는 경쟁 상태불 안 개념을 이해하는데 중요한 요인임을 확인할 수 있었다.

본 연구에서 나타나는 한계점을 바탕으로 후속 연구를 제언하고자 한다. 첫째, 본 연구는 경쟁 불안의 개념을 이해하고자 자기-제시 이론을 바 탕으로 구조방정식 관계 검증이 진행되었다. 후속 연구에서는 다양한 종 목과 선수의 경기력 수준에 따른 자기-제시와 경쟁불안의 관계를 구체 적으로 검증한다면 선수들의 경쟁불안의 원인을 실증적으로 파악하는 데 도움이 될 것이라 판단된다.

둘째, 선수들의 경쟁불안은 다양한 원인에서 나타난다. 국외 선행연구 에서 자기-제시는 운동선수에게 무의식적으로 나타날 수 있으며, 경쟁 불안의 원인을 단정 지을 수 없다는 의견이 제시되었다. 후속 연구에서 는 자기-제시와 더불어 부상, 환경적 요소 등을 함께 경쟁불안의 원인을 규명한다면 좀 더 넓은 의미에서 선수들의 불안을 이해할 수 있을 것이 라 판단된다.

셋째, 자기-제시와 다양한 심리적 상태의 연관성을 검증한다면, 운동 선수의 경기 전, 중, 후의 심리상태를 결정짓는데 기초자료가 될 것이다.

\section{참고문헌}

Craft, L. L., Magyar, T. M., Becker, B. J., \& Feltz, D. L. (2003). The relationship between the competitive stateanxiety inventory- 2 and sport performance: A meta-analysis. Journal of Sport \& Exercise Psychology, 25, 44-65.

Dias, C., Cruz, J. F., \& Fonseca, A. M. (2010). Coping strategies, multidimensional competitive anxiety and cognitive threat appraisal: differences across sex, age and type of sport. Serb. Journal of Sports Science. 4, 23-31.

Eysenck, M. W., Calvo, M. G. (1992). Anxiety and performance: The processing efficiency theory. Cognition \& Emotion, 6(6), 409434.

Goffman, E. (1959). The moral career of the mental patient. Psychiatry, 22(2), 123-142.

Hanin, Y. L. (2000). Successful and poor performance and emotions. In Y.L. Hanin (Ed.), Emotions in sport (pp. 157-187). Champaign, IL: Human Kinetics.

Hill, D. M., Carvell, S., Mattews, N., Weston, N. J. V., \& Thelwell, R. R. C. (2017). Exploring choking experiences in elite sport: The role of self-presentation. Psychology of Sport and Exercise, 33, 141-149.

Kim, Y. S., Youn, S. J., Park, I. C., \& Song, Y. G. (2020). I Worry How Other People Perceive Me in Competition: The Examination of Construct Validity in Self-presentation in Sport Questionnaires. Journal of Korean Association of Physical Education and Sport for Girls and Women. 34(2), 49-63.

Lazarus, R. S. (1999). Stress and emotion: A new synthesis. New York: Springer Publishing.

Lazarus, R. S. (2000). Cognitive-motivational-relational theory of emotion. In Y. L. Hanin (Ed.), Emotions in sport (pp. 39-63). Champaign, IL: Human Kinetics.

Lazarus, R. S., \& Folkman, S. (1984). Stress, appraisal, and coping. New York: Springer Publishing.

Leary, M. R. (2001). Social anxiety as an early warning system: arefinement and extension of the self-presentation theory of social anxiety. In Social Anxiety to Social Phobia: Multiple Perspectives. Edited by Hoffman SG, DiBartolo PM. Allyn. 321334.

Leary, M. R. (1992). Self-presentational processes in exercise and sport. Journal of Sport and Exercise Psychology, 14, 339-351.

Leary, M. R., \& Jongman-Sereno, K. P. (2014). Social anxiety as an early warning system: A refinement and extension of the selfpresentation theory of social anxiety. Social Anxiety, 3, 579-597.

Leary, M., \& Kowalski, R. M. (1990). Impression management: A literature review and two component model. Psychological Bulletin, 107, 34-47.

Lorimer, R. (2006). The relationship between self-presentational concerns and competitive anxiety: The influence of gender. International Journal of Sport and Exercise Psychology, 37, 317-329. 
Martin, K. A., \& Mack, D. (1996). Relationships between physical self-presentation and sport competition trait anxiety: A preliminary study. Journal of Sport and Exercise Psychology, 18, 75-82.

Martens, R., Vealey, R. S., \& Burton, D. (1990). Competitive anxiety in sport. Champaign, IL: Human Kinetics.

Mesagno, C., Geukes, K., \& Larkin, P. (2015). Choking under pressure: areview of current debates, literature, and interventions. In Contemporary Advances in Sport Psychology: A Review. Edited by Mellalieu S, Hanton S. Routledge. 148-174.

Mesagno C, Harvey J. T., \& Janelle C. M. (2011). Self-presentation origins of choking: evidence from separate pressure manipulations. Journal of Sport and Exercise Psychology, 33, 441-459.

McGowan, E., Prapavessis, H., \& Wesch, N. (2008). Selfpresentational concerns and competitive anxiety. Journal of Sport \& Exercise Psychology, 30(3), 383-400.

Nicholls, A. R., \& Thelwell, R. C. (2010). Coping conceptualized and unraveled. In A. R. Nicholls (Ed.), Coping in Sport: Theory, methods, and related constructs (pp. 3-14). New York: Nova Science.

Ntoumanis, N., \& Biddle, S. J. H. (2000). Relationship of intensity and direction of competitive anxiety with coping strategies. The Sport Psychologist, 14(4), 360-371.

Parfitt, C. G., Jones, J. G., \& Hardy, L. (1990). Multidimensional anxiety and performance. In J. G. Jones \& L. Hardy (Eds.), Stress and performance in sport (pp. 43-80). Chichester, England: Wiley.

Podlog, L., Lochbaum, M., Kleinert, J., Dimmock, J., Newton, M., \& Schulte, S. (2013). The relationship between self-presentation concerns and pre-game affect among adolescent American football players. Journal of Sport and Health Science, 2(3), 168-175.

Schlenker, B. R. (1980). Impression management: The self-concept, social identity, and interpersonal relations. Monterey, CA: Brooks/Cole.

Shin, J. T., Kim, J. S. (2005). The Effects of Stress Management Interventions on Trait Anxiety and Coping Skill of Female Athletes in Middle School. Korean journal of physical education. 44(4), 251-259.

Skinner, E. A., \& Zimmer-Gembeck, M. J. (2007). The development of coping. Annual Review of Psychology, 58, 119-144.

Steiger, J. H. (1990). Structural model evaluation and modification: An interval estimation approach. Multivariate behavioral research, 25(2), 173-180

Tamminen, K. A., Crocker, P. R. E. \& McEwen, C. E. (2014). Emotional experiences and coping in sport: How to promote positive adaptational outcomes in sport. In R. Gomes (Ed.). Positive human functioning from a multidimensional perspective. Nova Science.

Tseelon, E. (1992). In the presented self sincere? Goffman, impression management and the post modern self. Theory, Culture and Society, 9, 115-128.
Williams, M., Hudson, J., \& Lawson, R. J. (1999). Self-presentation in sport: Initial development of a scale for measuring athletes' competitive self-presentation concerns. Social Behavior and Personality, 27, 487-502.

Wilson, P., \& Eklund, R. C. (1998). The relationship between competitive anxiety and self-presentational concerns. Journal of Sport and Exercise Psychology, 20, 81-97.

Woodman, T., \& Hardy, L. (2001). Stress and anxiety. In R.N. Singer, H.A. Hausenblas, \& C.M. Janelle (Eds.), Handbook of sport psychology (2nd ed., pp. 290-318). New York, NY: Wiley.

Yoo, J., \& Park, S. J. (1998). Development and validation of the sport coping scale. Korean journal of physical education, 37(2), 151168. 


\section{엘리트 운동선수의 자기-제시와 경쟁 상태불안의 관계에서 스트레스 대처의 매개효과}

윤서진', 장태석2

1 상명대학교 전임연구교수

2 한국스포츠정책과학원 분석연구원

[목적] 본 연구는 국내 엘리트 운동선수를 대상으로 자기-제시, 스트레스 대처, 경쟁 상태불안의 관계를 검증하고 자기제시와 경쟁 상태불안의 관계에서 스트레스 대처의 매개효과를 확인하는데 목적이 있다.

[방법] 총 259명의 엘리트 운동선수를 대상으로 SPSS프로그램과 AMOS프로그램을 활용하여 관계검증을 진행하였다.

[결과] 첫째, 엘리트 운동선수의 자기-제시와 스트레스 대처는 유의한 정적 영향이 나타났다. 둘째, 엘리트 운동선수의 스트레스 대처와 경쟁 상태불안은 유의한 정적 영향이 나타났다. 셋째, 엘리트 운동선수의 자기-제시와 경쟁상태불안은 유의한 정적 영향이 나타났다. 마지막으로 엘리트 운동선수의 자기-제시와 경쟁 상태불안 관계에서 스트레스 대처는 매 개역할을 하는 것으로 나타났다.

[결론] 본 연구 결과를 통해 선수들이 느끼는 경쟁 불안은 자기-제시의 의미에 의존한다고 볼 수 있으며, 더 나아가 스트 레스 대처는 경쟁 불안과 깊은 관련이 있음을 알 수 있었다. 결론적으로 선수들의 경쟁불안을 다방면으로 이해할 수 있는 기초 자료를 제공하였다고 판단된다.

주요어

엘리트 운동선수, 자기-제시, 스트레스 대처, 경쟁 상태불안 